\title{
Lifestyle habits of adults during the COVID- 19 pandemic lockdown in Cyprus: evidence from a cross-sectional study
}

\author{
Ourania Kolokotroni ${ }^{1 *}{ }^{*}$, Maria C. Mosquera ${ }^{1 \dagger}$, Annalisa Quattrocchi $^{1}$, Alexandros Heraclides ${ }^{1}$, \\ Christiana Demetriou ${ }^{1}$ and Elena Philippou ${ }^{2,3}$
}

\begin{abstract}
Background: The COVID-19 pandemic and the widespread adoption of virus control measures have inevitably disrupted efforts to address lifestyle risk factors for non-communicable diseases (NCD). This study aimed to explore the effects of COVID-19 lockdown on all lifestyle medicine pillars, namely diet, physical activity, sleep, stress, social support and use of risky substances.

Methods: This was a cross-sectional study on a convenient sample of adults who resided in Cyprus during the Spring 2020 lockdown. Participants completed an anonymous online questionnaire comprised of six validated tools regarding the following lifestyle behaviours before and during lockdown: adherence to the Mediterranean diet, physical activity, stress and social support levels, sleep pattern and use of risky substances such as smoking and alcohol. Paired before and during lockdown comparisons for each lifestyle pillar were undertaken using Wilcoxon Signed-Rank test and Bowker symmetry Test where response was numerical (non-parametric data) and categorical respectively. Furthermore, stratified analyses for sociodemographic characteristics were performed.
\end{abstract}

Results: Out of 745 participants, $74 \%$ were female and median age was 39 years. Overall participants reported significantly higher perceived stress score ( $22 \vee 25, p<0.01$ ), lower social support score (71 $\vee 68, p<0.001$ ), and worse sleep quality score $(4 \vee 5, p<0.01)$ during lockdown. Mediterranean diet $(M D)$ adherence was moderate and increased significantly only in those practicing religious fasting (score of $6 \vee 7, p<0.01$ ). Total minutes spent sitting increased (120 v 180, $p<0.01)$ although overall physical activity score did not significantly change. Smoking intensity increased during lockdown whilst frequency of alcohol consumption decreased ( $p_{\text {trend }}=0.03$ and $<0.01$, respectively).

Conclusion: Various lifestyle factors were adversely affected by the COVID-19 lockdown in Cyprus. Evidence from this study supports development of holistic lifestyle interventions during and following the pandemic to reduce short and long-term NCD risks by building on lifestyle behaviour strengths and addressing longstanding and emerging gaps and needs.

Keywords: Lifestyle, Coronavirus pandemic, COVID-19, Lockdown, Mediterranean diet, Physical activity, Stress, Sleep, Social support, Addictions

\footnotetext{
* Correspondence: kolokotroni.o@unic.ac.cy

${ }^{\dagger}$ Ourania Kolokotroni and Maria C. Mosquera contributed equally to this work.

'Department of Primary Care and Population Health, Medical School, University of Nicosia, 21 Ilia Papakyriakou, 2414, Engomi, P.O. Box 24005, CY-1700 Nicosia, Cyprus

Full list of author information is available at the end of the article
}

(c) The Author(s). 2021 Open Access This article is licensed under a Creative Commons Attribution 4.0 International License, which permits use, sharing, adaptation, distribution and reproduction in any medium or format, as long as you give appropriate credit to the original author(s) and the source, provide a link to the Creative Commons licence, and indicate if changes were made. The images or other third party material in this article are included in the article's Creative Commons licence, unless indicated otherwise in a credit line to the material. If material is not included in the article's Creative Commons licence and your intended use is not permitted by statutory regulation or exceeds the permitted use, you will need to obtain permission directly from the copyright holder. To view a copy of this licence, visit http://creativecommons.org/licenses/by/4.0/. The Creative Commons Public Domain Dedication waiver (http://creativecommons.org/publicdomain/zero/1.0/) applies to the data made available in this article, unless otherwise stated in a credit line to the data. 


\section{Introduction}

Despite the fact that the world is currently immersed in a global coronavirus (COVID-19) pandemic [1], it is of importance that, globally, non-communicable diseases (NCDs), such as cardiovascular diseases, cancer, and diabetes, remain notable causes of morbidity and mortality [2]. Lifestyle modifiable behaviours, such as unhealthy diets, physical inactivity, tobacco use, and harmful use of alcohol, pose significant risk factors for NCDs [3]. Concurrently, lifestyle factors such as smoking, alcohol use, physical inactivity and obesity, have been identified as risk factors for adverse COVID-19 outcomes [4-7].

Globally, there is concern that the current COVID-19 pandemic has disrupted progress in addressing lifestyle factors to decrease morbidity and mortality [2]. Widespread measures to combat the current COVID-19 pandemic that encourage or require social distancing, self-isolation, in-home lockdown, and/or quarantine undermine attempts towards a healthy lifestyle and pose a mental health threat [8]. A growing number of studies have investigated individual lifestyle habits such as diet, physical activity, stress, sleep and addictions during the first phase of the pandemic and confirmed that in many cases lockdown and other important measures to limit the spread of virus have adversely affected lifestyle habits [9-11]. For example, lockdown measures limited exercise opportunities, reduced physical activity levels, [9, 10, 12], increased food consumption, affected diet quality $[11,13]$, and impacted sleep [14]. Furthermore, quarantine has been associated with negative psychological effects, including post-traumatic stress symptoms, confusion, and anger with multiple stressors identified, such as longer lockdown duration, infection fears, frustration, boredom, inadequate supplies, inadequate information, stigma, and financial loss [15]. Not surprisingly, during these unprecedented experiences being faced globally due to the COVID19 pandemic, the wellbeing of people, in the form of stress, anxiety and sleep disturbances, was also affected [16-18].

A smaller number of studies attempted to assess changes in a combination of lifestyle habits or investigate correlations between them $[19,20]$. For example, a study in 1254 adults in Spain evaluated lifestyle across 7 domains using the Short Multidimensional Inventory Lifestyle Evaluation tool developed specifically for the lockdown and showed that healthier habits were associated with higher social support, stress management and higher outdoor exposures [19]. Similarly, another study in the Spanish population showed that several healthrelated behaviors were adversely affected in the first week of lockdown but improved with longer confinement [20]. However, more studies are needed on a comprehensive assessment across a range of lifestyle habits as globally, various measures, some prolonged, targeting movement restriction, such as lockdown, are still in use.
The field of lifestyle medicine is well equipped to address lifestyle factors, as it aims to utilize an evidencebased approach to prevent, treat and even reverse diseases by encouraging healthy behaviours across the six pillars of lifestyle: healthy eating, physical activity, restful sleep, stress management, avoidance of risky substances such as alcohol and smoking, and healthy relationships [21]. This comprehensive approach of combining healthy lifestyle behaviours is known to be associated with increased disease-free life-years [3] and decreased mortality [22]. Thus, assessing needs based on this approach will be important for the design of lifestyle interventions during this period.

Thus, our study aimed to investigate lifestyle changes across all lifestyle pillars in adults in Cyprus during the first phase of the COVID-19 pandemic, where a lockdown was implemented between 15th March and 21st May 2020. This study aims to inform relevant stakeholders on the well-being priority needs of a population which practices social distancing or is in lockdown thereby aiding the design of holistic lifestyle interventions targeting multiple health behaviours both during and after social distancing to reduce the risk of chronic disease in the short and long term.

\section{Methods}

\section{Design and setting}

This was a cross-sectional web-based questionnaire survey conducted between 10th April and 12th May 2020, designed and performed in accordance with the Declaration of Helsinki. A convenience sample was recruited through social media and institutional and community social network mailing lists. Study participation was anonymous and informed consent was obtained before study enrollment. Following self-completion of the study questionnaire either in the Greek or English language, participants received digital educational material with practical tips on ways to maintain a healthy lifestyle during lockdown.

The Cyprus lockdown was gradual and started on March 10th 2020 with the closure of schools and universities and the prohibition of gatherings of more than 75 people. This was followed by closure of entertainment areas (e.g., malls, hotels, cinemas) and the application of the " 1 person per 8 square meters" measure to all public areas on March 15th 2020. On March 24th, the majority of retail stores closed. The country went into a strict lockdown between 31st March and May 3rd when airports were closed (repatriation allowed and individuals arriving from abroad were isolated in quarantine hotels for 14 days), a night curfew was implemented and an "once a day" allowance of going out of the house was given for essential movements. Gatherings were prohibited and intercity movements were only allowed for essential 
work. Between May 3rd and May 21st, daily allowance to go out of the house increased to maximum of 3 times per day. After May 21st, there was a gradual lifting of restriction measures [23].

\section{Study population}

The study population consisted of adults $\geq 18$ years who were living in Cyprus during the period of the Spring 2020 lockdown.

\section{Assessment tools}

The study questionnaire consisted of six widely used tools validated in both English and Greek in order to assess the six pillars of lifestyle medicine: nutrition, physical activity, sleep, stress, social connection, and risky substance use (alcohol). It also included questions on socio-demographic characteristics of participants, including self-reported height and weight, and questions assessing tobacco use. Participants were asked to provide their responses concerning: (a) February 2020, the month preceding the emergence of coronavirus in Cyprus and (b) the period in lockdown.

The validated tools used were the: (a) Mediterranean Diet Adherence Screener (MEDAS) [24], (b) International Physical Activity Questionnaire (IPAQ) [25], (c) the Pittsburgh Sleep Quality Index (PSQI) [26], (d) Perceived Stress Scale-14 (PSS-14) [27], (e) the Medical Outcomes Study - Social Support Survey (MOS-SSS) [28], and (f) Alcohol Use Disorders Identification Test (AUDIT-C) [29].

\section{Statistical analysis}

Scores were calculated in line with published toolspecific scoring instructions. Descriptive analyses were performed to calculate absolute and relative frequencies for categorical variables and median and interquartile ranges (IQR) for numerical variables. To evaluate the effects of lockdown on socioeconomic, anthropometric and lifestyle questions, paired before (referring to month of February) and after (referring to the time during lockdown) comparison was undertaken. Wilcoxon SignedRank test and Bowker symmetry Test were performed for questions where response was numerical and categorical respectively. Non parametric tests were used as numerical variables were checked and were not found to follow normal distribution. Participants with missing values in an outcome variable were excluded from any analysis on that variable.

Paired before and during lockdown comparisons for MD adherence, IPAQ, PSQI, MOS-SSS PSS-14 and AUDIT-C scores were performed for the overall cohort, as well as stratified by independent sociodemographic variables, such as age group, gender, nationality, education level, marital status, number of people living in the household, residence in urban/rural areas, employment status, change in working conditions, baseline household monthly net income and change in monthly income. Lastly, before and during lockdown differences in $\mathrm{MD}$ adherence, IPAQ, PSQI, MOS-SSS, PSS-14 and AUDIT$\mathrm{C}$ scores were correlated between them, while adjusting for age and gender (and fasting status for MD adherence), using partial Spearman's rank correlation. A $p$-value < 0.05 was regarded as significant in all analyses. Statistical analyses were performed using STATA ${ }^{\circ}$ v.16 (StataCorp., USA) and R statistical software packages.

\section{Results}

\section{Participant characteristics}

The socio-demographic characteristics of the 745 participants are presented in Table 1. Briefly, the median age was 39 years (IQR: 13 years); $73.8 \%$ were female. The great majority lived in urban areas (85.0\%) and had attained university education at undergraduate $(40.0 \%)$ or postgraduate level (50.3\%). Two thirds of participants were employed (66.3\%) and married, living with a partner or in a partner relationship (61.2\%). Almost half (46.9\%) had a baseline household net-income $<2000$ euro per month. During the lockdown, working conditions changed for three in four participants (74.4\%). Among them, 39.1\% worked more hours, 36.7\% worked less hours and $24.3 \%$ suspended work. Among those working, $63.8 \%$ worked from home, $9.4 \%$ went to the workplace, and $18.5 \%$ did both. Overall, $74.2 \%$ did not report any diagnosed health conditions.

\section{Comparison of lifestyle habits before and during lockdown}

In Table 2, the lifestyle habits of participants (Diet, Physical Activity, Stress, Sleep, Social Connection and Use of Risky Substances) are compared before and during lockdown. Most lifestyle habits were adversely affected during lockdown, as indicated by changes in the overall median questionnaire scores and the shift in score distribution towards worsening values (Supplementary Figure 1). Changes in scores within individual areas of each lifestyle pillar are presented in more detail in Supplementary Tables 1, 2, 3, 4 and 5.

MD adherence remained moderate during lockdown (median 6, IQR 3) although one-third of participants reported a higher score $(31.9 \%)(p<0.01)$. In particular, there was increased consumption of most components of the MD including those healthy (e.g., fruit, vegetables, legumes) and less healthy (e.g., sweet beverages and commercial sweets), whereas preferential consumption of white vs. red meat did not change. Subgroup analyses demonstrated that increased adherence was only significant among participants who started fasting, as per the Greek Orthodox religion, during lockdown. Among these 
Table 1 Socio demographic and health related characteristics

\begin{tabular}{|c|c|c|c|}
\hline \multirow[t]{2}{*}{ Socio-demographic characteristics } & & \multicolumn{2}{|c|}{ Total $(n=745)^{\mathrm{a}}$} \\
\hline & & $\bar{N}$ & $\%$ \\
\hline \multirow[t]{2}{*}{ Gender } & Female & 550 & 73.8 \\
\hline & Male & 195 & 26.2 \\
\hline Age & Median (IQR) & 39 (13) & \\
\hline \multirow[t]{4}{*}{ Age groups } & $18-29$ & 218 & 29.3 \\
\hline & $30-39$ & 162 & 21.7 \\
\hline & $40-49$ & 174 & 23.4 \\
\hline & $50-76$ & 191 & 25.6 \\
\hline \multirow[t]{4}{*}{ Nationality } & Cypriot & 603 & 81.3 \\
\hline & Greek & 75 & 10.1 \\
\hline & European & 41 & 5.5 \\
\hline & Other & 23 & 3.1 \\
\hline \multirow[t]{2}{*}{ Area } & Urban area (city) & 633 & 85.0 \\
\hline & Rural area (village) & 112 & 15.0 \\
\hline \multirow[t]{4}{*}{ Educational attainment } & Primary (Primary school) & 2 & 0.3 \\
\hline & Secondary (High School) & 70 & 9.4 \\
\hline & Tertiary (University / College at undergraduate level) & 298 & 40.0 \\
\hline & Tertiary (University / College postgraduate or doctoral level) & 375 & 50.3 \\
\hline \multirow[t]{5}{*}{ Employment status } & Student & 155 & 20.8 \\
\hline & Unemployed for the whole year & 22 & 3.0 \\
\hline & Unemployed for part of the year & 20 & 2.7 \\
\hline & Employed & 494 & 66.3 \\
\hline & Retired & 54 & 7.2 \\
\hline \multirow[t]{4}{*}{ Marital status } & Single & 232 & 31.1 \\
\hline & Married / Living together / Relationship & 456 & 61.2 \\
\hline & Divorced & 47 & 6.3 \\
\hline & Widowed & 10 & 1.3 \\
\hline N. of people in household & Median (IQR) & $3(2)$ & \\
\hline \multirow[t]{5}{*}{ Income in euro (in the Month before Lockdown) } & $<1000$ & 101 & 15.7 \\
\hline & $1000-2000$ & 200 & 31.2 \\
\hline & $2000-3000$ & 175 & 27.3 \\
\hline & $3000-4000$ & 92 & 14.3 \\
\hline & $>4000$ & 74 & 11.5 \\
\hline \multirow{3}{*}{$\begin{array}{l}\text { Have your working conditions changed during } \\
\text { the month in lockdown? }\end{array}$} & No & 95 & 12.8 \\
\hline & Yes & 552 & 74.4 \\
\hline & Not Applicable & 96 & 12.9 \\
\hline \multirow{3}{*}{$\begin{array}{l}\text { If yes, how have your working conditions } \\
\text { changed during the month in lockdown? }\end{array}$} & Working more hours & 211 & 39.1 \\
\hline & Working less hours & 198 & 36.7 \\
\hline & Not working & 131 & 24.3 \\
\hline \multirow{3}{*}{$\begin{array}{l}\text { If working different hours, has your place of work } \\
\text { changed during the month in lockdown? }\end{array}$} & Working from home only & 293 & 63.8 \\
\hline & Working outside of home only & 43 & 9.4 \\
\hline & Working both from home and outside of home & 85 & 18.5 \\
\hline
\end{tabular}

\section{Health related characteristics}

$\mathrm{BMI}$ in month before lockdown 
Table 1 Socio demographic and health related characteristics (Continued)

\begin{tabular}{|c|c|c|c|}
\hline \multirow[t]{2}{*}{ Socio-demographic characteristics } & & \multicolumn{2}{|c|}{ Total $(n=745)^{\mathrm{a}}$} \\
\hline & & $\mathrm{N}$ & $\%$ \\
\hline BMI in lockdown & Median (IQR) & 24.2 & \\
\hline \multirow{2}{*}{$\begin{array}{l}\text { Were you fasting during the month of } \\
\text { lockdown? }\end{array}$} & No & 559 & 75.0 \\
\hline & Yes & 186 & 25.0 \\
\hline \multirow{2}{*}{$\begin{array}{l}\text { Do you currently have any diagnosed health } \\
\text { conditions? }\end{array}$} & No & 553 & 74.2 \\
\hline & Yes & 192 & 25.8 \\
\hline
\end{tabular}

${ }^{a}$ Missing values: nationality (3), income in euros (103), Have your working conditions changed during the month in lockdown? (2), If yes, how have your working conditions changed during the month in lockdown? (12), If yes, has your place of work changed during the month in lockdown? (26), BMI in month before lockdown (3), BMI in lockdown (2)

participants (25\% of total study population), median MD adherence score increased by 1 unit $(p<0.01)$. Of note, Body Mass Index (BMI) increased slightly but significantly during lockdown (24.2 vs. 24.0, $p<0.01)$.

As expected, increasing sedentary behaviour was reported by most participants during lockdown (180 vs.120 min sitting, $p<0.01$ ). However, the overall physical activity score did not significantly change $(p=0.95)$; $60 \%$ of participants did not report any change and the remaining $40 \%$ were split between increased and decreased activity levels. However, there was a significant increase in the average weekly energy daily expenditure in walking during lockdown (Supplementary Table 2, MET (one Metabolic Equivalent - min/week 297 vs. 231, $p<0.01)$. In contrast, MET-min/week spent in moderate or vigorous physical activity were lower during the lockdown period, albeit non-significant except in younger participants (18-29-year-old, students).

Being in lockdown was also significantly associated with an increase in perceived stress (25 vs. $22, p<0.01$ ). Almost 6 in 10 participants (57.9\%) reported higher stress scores during lockdown. Similarly, sleep quality was negatively affected; the median Global PSQI score significantly increased (5 vs. $4, p<0.01$ ) and one in two participants reported worsening scores. Moreover, the proportion of participants with poor sleep quality (global PSQI score $>5)$ increased during lockdown $(40.4 \% \mathrm{v}$ $26.0 \%, p<0.01)$. Regarding the individual PSQI score components (sleep latency, daytime dysfunction, sleep medication and sleep quality), all increased during lockdown $(p<0.01)$, demonstrating a worse sleep experience, except sleep efficiency, which marginally improved during lockdown $(p<0.01)$. Social support was also adversely impacted: the overall support index decreased significantly in lockdown (68.4 vs. 71.1, $p<0.01)$, almost half of the participants (43.6\%) reported lower support scores. A significant decrease was observed in all overall support index components, namely emotional/informational support, tangible support, affectionate support and positive social interaction $(p<0.01)$.
Pertaining substance use, $43.8 \%$ of smokers increased their smoking intensity during the month in lockdown $(p<0.03)$. In contrast, the median AUDIT-C score decreased significantly in lockdown ( 2 vs $1, p<0.01)$ as a consequence of the reduction in the overall frequency but also quantity of alcohol consumption. Indicatively, $26 \%$ of the sample decreased consumption frequency compared to $11.5 \%$ who increased consumption, while abstinence also increased (36.2\% v 22.3\%). Regarding quantity of consumption, even though the number of alcoholic drinks per day did not change significantly $(p=0.08)$, more participants reported a decrease rather than an increase in the frequency of binge drinking ( $\geq 6$ alcoholic drinks on one occasion) during lockdown (11.6\% vs. $3.1 \%, p<0.01)$. Similarly, the proportion of high-risk drinkers defined as per the AUDIT -C score decreased in lockdown (22.7\% vs $20.2 \%$, $p=0.06)$, whilst this decrease was more pronounced in men (29.4\% vs $23.3 \%, p=0.04$, data not shown).

Stratified analysis by socio-demographic characteristics (data not shown) showed that sleep, social support and stress scores increased significantly across all socioeconomic strata. Physical activity levels decreased in the younger age and student groups. Nonetheless, higher MD adherence was seen in both genders, younger (18-29 y.o) and older age groups (50-76 y.o.), those living in urban areas, and those with higher educational attainment.

\section{Correlation between differences in lifestyle scores during lockdown}

In Table 3, the correlations between before and during lockdown differences in lifestyle scores, adjusted for potential confounders, are shown. Weak to moderate significant associations were observed between perceived stress and sleep quality index, overall support index and perceived stress, and between overall support index and sleep quality index. More specifically, a positive moderate correlation $(r=0.4064, p<0.01)$ between differences in perceived stress and sleep quality index before and during lockdown, indicating that an increase in perceived stress was associated with worsening sleep quality. Overall 
Table 2 Lifestyle habits (Diet, Physical activity, Stress, Sleep, Social connection, Use of risky substances) before and during lockdown

\begin{tabular}{|c|c|c|c|c|c|}
\hline \multirow[t]{2}{*}{ Lifestyle habits } & \multirow{2}{*}{$\begin{array}{l}\text { The Month before Lockdown } \\
\text { Median (IQR) }^{\text {a }}\end{array}$} & \multirow[t]{2}{*}{ Lockdown } & \multicolumn{2}{|c|}{$\begin{array}{l}\text { Change in score } \\
\text { (\% of participants) }\end{array}$} & \multirow[t]{2}{*}{$P$ value ${ }^{c}$} \\
\hline & & & Decrease & Increase & \\
\hline \multicolumn{6}{|l|}{ Diet } \\
\hline Mediterranean Diet Score (range: 0-14) & $6(2)$ & $6(3)$ & 22.7 & 31.9 & $<0.01$ \\
\hline \multicolumn{6}{|l|}{ Physical Activity } \\
\hline MET & $792(1880)$ & $813(1815)$ & 37.0 & 43.8 & 0.16 \\
\hline Time spent sitting (mins) & $120(340)$ & $180(466)$ & 14.5 & 67.1 & $<0.01$ \\
\hline \multicolumn{6}{|l|}{ Physical Activity Score (\%) } \\
\hline Low & $49.4 \%$ & $48.9 \%$ & 21.2 & 21.5 & 0.95 \\
\hline Moderate & $25.2 \%$ & $26.3 \%$ & & & \\
\hline High & $25.4 \%$ & $24.8 \%$ & & & \\
\hline \multicolumn{6}{|l|}{ Stress } \\
\hline PSS-14 overall score (0-56) & $22(9)$ & $25(12)$ & 21.7 & 57.9 & $<0.01$ \\
\hline \multicolumn{6}{|l|}{ Sleep } \\
\hline Global PSQI score (range: 0-21) & $4(4)$ & $5(4)$ & 25.3 & 49.1 & $<0.01$ \\
\hline Sleep latency (0-3) & $1(1)$ & $1(2)$ & 6.1 & 40.6 & $<0.01$ \\
\hline Daytime dysfunction (0-3) & $1(1)$ & $1(1)$ & 12.3 & 28.5 & $<0.01$ \\
\hline Sleep efficiency (0-3) & $0(1)$ & $0(0)$ & 15.6 & 14.1 & $<0.01$ \\
\hline Sleep medication (0-3) & $0(0)$ & $0(0)$ & 1.2 & 4.3 & $<0.01$ \\
\hline Sleep quality (0-3) & $1(1)$ & $1(2)$ & 10.1 & 26.8 & $<0.01$ \\
\hline \multicolumn{6}{|l|}{ Social Support } \\
\hline Overall Support Index (0-100) & $71.1(31.58)$ & $68.4(36.8)$ & 43.6 & 18.0 & $<0.01$ \\
\hline Emotional/informational support & $71.9(37.5)$ & $65.6(40.6)$ & 28.9 & 12.5 & $<0.01$ \\
\hline Tangible support & $75.0(43.8)$ & $75(43.75)$ & 20.7 & 13.4 & $<0.01$ \\
\hline Affectionate Support & $75.0(50)$ & $75(50)$ & 24.6 & 9.7 & $<0.01$ \\
\hline Positive Social Interaction & $75.0(50)$ & $66.7(58.3)$ & 34.0 & 11.0 & $<0.01$ \\
\hline \multicolumn{6}{|l|}{ Use of Substances } \\
\hline Cigarettes, cigars and e-cigarettes (total n) & $10(14)$ & $10(8)$ & 28.1 & 43.8 & 0.03 \\
\hline Alcohol Use Disorders Identification Test (AUDIT-C) & $2(2)$ & $1(2)$ & 29.4 & 11.5 & $<0.01$ \\
\hline \multicolumn{6}{|l|}{$\begin{array}{l}\text { Alcohol Use Disorders Identification Test (AUDIT-C) } \\
\text { score risk (\%) }\end{array}$} \\
\hline No or low risk & $77.2 \%$ & $79.8 \%$ & 7.04 .6 & 4.67 .0 & 0.06 \\
\hline High risk & $22.7 \%$ & $20.2 \%$ & & & \\
\hline \multicolumn{6}{|l|}{ Frequency of alcohol consumption (\%) } \\
\hline Never & $22.3 \%$ & $36.2 \%$ & 26.0 & 11.5 & $<0.01$ \\
\hline Monthly or less & $29.4 \%$ & $27.2 \%$ & & & \\
\hline $2-4$ times a month & $33.2 \%$ & $19.9 \%$ & & & \\
\hline 2-3 times a week & $10.3 \%$ & $8.9 \%$ & & & \\
\hline 4 or more times a week & $4.8 \%$ & $7.8 \%$ & & & \\
\hline \multicolumn{6}{|l|}{ Number of alcoholic drinks on a typical day (\%) } \\
\hline 0 & $53.1 \%$ & $57.5 \%$ & 13.1 & 9.1 & 0.08 \\
\hline 1 or 2 & $39.3 \%$ & $36 \%$ & & & \\
\hline 3 or 4 & $6.0 \%$ & $4.8 \%$ & & & \\
\hline 5 or 6 & $1.2 \%$ & $1.1 \%$ & & & \\
\hline 7,8 or 9 & $0.3 \%$ & $0.3 \%$ & & & \\
\hline
\end{tabular}


Table 2 Lifestyle habits (Diet, Physical activity, Stress, Sleep, Social connection, Use of risky substances) before and during lockdown (Continued)

\begin{tabular}{|c|c|c|c|c|c|}
\hline \multirow[t]{2}{*}{ Lifestyle habits } & \multirow{2}{*}{$\begin{array}{l}\text { The Month before Lockdown } \\
\text { Median (IQR) }^{\text {a }}\end{array}$} & \multirow[t]{2}{*}{ Lockdown } & \multicolumn{2}{|c|}{$\begin{array}{l}\text { Change in score }{ }^{b} \\
\text { (\% of participants) }\end{array}$} & \multirow[t]{2}{*}{$P$ value ${ }^{c}$} \\
\hline & & & Decrease & Increase & \\
\hline 10 or more & $0.1 \%$ & $0.3 \%$ & & & \\
\hline \multicolumn{6}{|c|}{ Six or more alcoholic drinks on one occasion (\%) } \\
\hline Never & $78.6 \%$ & $88.3 \%$ & 11.6 & 3.1 & $<0.01$ \\
\hline Less than Monthly & $12.2 \%$ & $6.3 \%$ & & & \\
\hline Monthly & $6.6 \%$ & $2.9 \%$ & & & \\
\hline Weekly & $2.5 \%$ & $1.8 \%$ & & & \\
\hline Daily or Almost Daily & $0.1 \%$ & $0.7 \%$ & & & \\
\hline
\end{tabular}

${ }^{a}$ Questionnaire Scores for reporting different lifestyle pillar habits are presented as median values (IQR) with the exception of alcohol consumption where the percentage of participants per consumption frequency is presented. The MEDAS score ranges from 0 to 14 , with higher scores indicating higher adherence to the Mediterranean Diet. The IPAQ score, categorizes participants into levels of Low, Moderate and High physical activity. The PSQI score, ranging from 0 to 21, assesses sleep quality with higher scores $(>5)$ representing poor sleep quality. The MOS-SSS ranges from 0 to 100 with higher scores indicating higher levels of social support. The PSS-14 score ranges from 1 to 14, and higher scores are associated with increased perceived stress. The AUDIT-C score ranges from 0 to 12 ; a score of 4 or more in men and a score of 3 or more in women is indicates elevated risk for hazardous drinking or active alcohol use disorder. Missing values for all responses included in score calculations were in the range of $<5 \%$

${ }^{\mathrm{b}}$ Change in score refers to the Month in Lockdown compared to February 2020 (i.e. - the Month before Lockdown)

'Signrank test was used for the comparison of median questionnaire scores between February 2020 (i.e. - the Month before Lockdown) and lockdown and Bowker symmetry Test for comparison of categorical variables

support index score difference was negatively correlated with perceived stress difference $(r=-0.3742, p<0.01)$ and sleep quality index difference $(r=-0.2253, p<0.01)$, showing that a decrease in the overall support index during lockdown was associated with an increase in perceived stress and worsening sleep quality.

Lastly, significant but very small negative correlations were observed between differences in physical activity score and sleep quality index $(r=-0.0911, p=0.01)$ and perceived stress $(r=-0.0794, p=0.03)$. A decrease in physical activity scores during lockdown was associated both with worse sleep quality and increased perceived stress. Significant correlations were not observed between diet scores and any other lifestyle pillars.

\section{Discussion}

Summary of findings

Several studies evaluating lifestyle habits during the COVID-19 pandemic focussed on individual factors such as diet [11], physical activity [10] or psychological health $[9,18]$. To the best of our knowledge, our study is one of few that used a comprehensive approach to investigate changes across all six pillars of lifestyle medicine during the COVID-19 pandemic in adults before and during strict lockdown measures. It is also the first study in Cyprus to assess the lifestyle of the local people under these extraordinary circumstances. The study findings show most lifestyle behaviours were adversely affected. Specifically, participants reported being more stressed, having worse sleep quality and lower social support. Furthermore, though participants reported eating more in terms of portions, their quality of diet, however, did not seem to change, with average MD adherence score being moderate before and during lockdown. Overall, physical activity score did not change during lockdown; however, there was an increase in energy expenditure in walking along with an increase in time spent sedentary. A large number of smokers reported increased smoking intensity

Table 3 Association between lifestyle habits during the month of lockdown ( ${ }^{\mathrm{a}}$ )

\begin{tabular}{lllll}
\hline & $\begin{array}{l}\text { Diet score } \\
\text { difference } \\
\boldsymbol{n}=\mathbf{7 4 5}\end{array}$ & $\begin{array}{l}\text { PA score } \\
\text { difference } \\
\boldsymbol{n}=\mathbf{7 4 5}\end{array}$ & $\begin{array}{l}\text { PSQI score } \\
\text { difference } \\
\boldsymbol{n}=\mathbf{7 2 7}\end{array}$ & $\begin{array}{l}\text { MOS-SSS score } \\
\text { difference } \\
\boldsymbol{n}=\mathbf{7 4 5}\end{array}$ \\
\hline $\begin{array}{l}\text { Diet score difference } \\
\text { PA score difference }\end{array}$ & $\begin{array}{l}\text { PSS-14 score } \\
\text { difference } \\
\boldsymbol{n}=\mathbf{7 4 5}\end{array}$ \\
PSQI score difference & $\begin{array}{l}r=0.0535 \\
p=0.15\end{array}$ & $r=1.0000$ & \\
MOS-SSS score difference & $\begin{array}{l}r=-0.0527 \\
p=0.16\end{array}$ & $\begin{array}{l}r=-0.0911 \\
p=0.01\end{array}$ & $r=1.0000$ & \\
PSS-14 score difference & $\begin{array}{l}r=0.0402 \\
p=0.27\end{array}$ & $\begin{array}{l}r=0.0329 \\
p=0.37\end{array}$ & $\begin{array}{l}r=-0.2253 \\
p<0.01\end{array}$ & $r=1.0000$ \\
& $r=-0.0627$ & $r=-0.0794$ & $r=0.4064$ & $r=-0.3742$ \\
$p=0.09$ & $p=0.03$ & $p<0.01$ & $p<0.01$ \\
\hline
\end{tabular}

${ }^{a}$ Spearman's rank Correlation analysis between score differences - All adjusted for Gender and Age, diet also adjusted for Fasting 
whereas overall alcohol consumption decreased. A significant correlation was observed between some lifestyle behaviours, with more pronounced effects seen between sleep, stress and social support.

\section{Main body}

Similar to other studies that assessed a range of lifestyle habits during lockdown [19, 20,30], our study showed consistent findings in regard to the adverse effects and the interlinked association of sleep, stress and social support. For example, the multi-country study by Ammar et al. of 1047 adults across 3 continents showed a positive correlation of mental health with higher social support and a negative correlation with poor sleep [30]. Similarly, the Spanish study of 1254 adults showed that higher social support, stress management and higher outdoor exposures were the most important factors associated with better health behaviours [19]. There was also agreement between our findings and those of the other studies in regard to the higher food consumption and sedentary time during lockdown [19, 20,30]. However, there was variation in the findings in regards to physical activity changes which could be explained by differences in restriction measures and population baseline physical activity levels [20,30].

Regarding our findings in each individual pillar and starting with diet during lockdown, participants in our study were affected in various ways. Firstly, diet quality, as reported by the MEDAS score, was moderate. Whilst diet quality seemed to improve in some areas but not in others during lockdown, there was an overall improved MD adherence score amongst participants who were fasting, as per the Greek Orthodox religion tradition. This is not surprising since fasting is a plant-based diet, thus closer to the original MD [31]. Agreeing with our study, adherence to MD during lockdown was moderate in an Italian study with 3533 participants aged 12-86 years. This study reported an increase in the sense of hunger and appetite as well as perceived weight gain in almost half of the participants [32]. Similarly, in another Italian study, half of participants reported higher food consumption as a result of eating more "comfort food" (sweets and salty snacks) but also fruits [11], whereas a study from Poland reported increased snacking between meals especially amongst the obese [33]. The ECLBCOVID19 International Online Survey also showed an increase in the number of meals and snacking during confinement and a higher unhealthy diet score [30]. However, the Spanish COVIDiet study, which also assessed adherence to MD before and after lockdown, adherence to the MD increased significantly from 6.53 $+/-2$ to $7.34+/-1.93$. COVIDiet participants with higher MD adherence decreased intake of sweet/carbonated beverages, red meat and pastries by $16-18 \%$, yet increased fruit and vegetable intake by around 12\% [34]. Similar to our findings, COVIDiet participants with postgraduate education had higher MD adherence.

Pertaining exercise, the average weekly activity score per participant in our population did not change during lockdown. These findings are in contrast to a recent systematic review on physical activity and sedentary behaviour during COVID19 lockdown in healthy adults which included 44 studies that in their majority did not use a validated PA measurement tool and suggested a reduction in physical activity levels of individuals in lockdown in most countries [12]. For example, an online survey of 1471 adults in Australia reported a negative change in the physical activity of almost half of the participants [9] whereas a study in Italy showed a significant decrease in the weekly MET-min score across all activity categories in 2524 adults [35]. However, just over $75 \%$ of the Italian participants had moderate or high physical activity levels before lockdown and the negative impact of lockdown was mostly seen in these individuals Similarly, the systematic review also showed that people with higher prelockdown physical levels were more likely to have a larger decrease in PA levels during lockdown [12]. This is in agreement with our findings that showed a decrease in physical activity levels only in those with moderate and vigorous pre-lockdown physical activity levels. In our study however, half of our participants had low physical activity levels. Individuals classified as low active before lockdown showed a significant increase in their physical activity levels in lockdown as demonstrated by the study of Rodrigo et al. in 1155 adults in Spain [13]. This can explain the fact that in our population, the number of participants who spent time walking increased during lockdown Walking is usually a preferred exercise amongst less active individuals [36]. Moreover, in Cyprus during spring, walking was likely a well-suited outdoor activity for families and seniors. This increase in energy expenditure in walking however was negated by the decrease in moderate and vigorous activity, thus explaining the overall picture of no change in physical activity in our population. Finally, and unsurprisingly, staying at home with a "once a day" allowance to go out led to an increase in the time participants spent sitting and in other sedentary activities, something evidenced by other studies $[9,35]$ and a recent systematic review on physical activity and sedentary behaviour during COVID-19 lockdown [12].

Sleep, stress, and social support are important interrelated factors in lifestyle medicine [21]. During the COVID-19 lockdown, significant associations were reported between them in studies that evaluated stress and sleep [16] and social support and stress [37]. To our knowledge, few other studies to-date have evaluated social support, sleep, and stress $[19,38]$. A smaller 
study $(n=170)$ in China evaluated persons under selfisolation [38] and showed that low levels of social capital were associated with increased stress, which in turn reduced sleep quality.

In our study, social support decreased during COVID19 lockdown, which differs from results seen in studies in the US [39] and Egypt [37], where social support increased. This difference may be driven by factors such as timing of the study and degree of lockdown measures as well as societal and cultural differences. Decreased social support in our study was associated with increased perceived stress $(r=-0.3742, p<0.01)$, related to findings of other studies showing the adverse effects of loneliness and lack of social support on stress and mental health during the COVID-19 pandemic [39-41]. Additionally, our study confirms other findings during the COVID-19 pandemic that higher perceived stress is associated with lower sleep quality [16] and that the proportion of those with poor sleep quality increased [42]. A recent systematic review and meta-analysis reported a global pooled prevalence rate of sleep problems of 35\% [14]. In our population and although global sleep quality significantly changed in our participants during lockdown (global PSQI score: 4 before vs. 5 during lockdown, $p<0.01$ ), it is noteworthy that both before and during lockdown our respondents, overall, had "good" sleep quality (global PSQI score $\leq 5$ ).

Given the association between stress, anxiety and substance use [43], smoking and alcohol consumption frequency and/or intensity during lockdown were expected to increase in some people due to higher stress levels and decrease in others who smoke or drink socially. Findings from our study confirm the above; $43.8 \%$ of smokers increased and $28.1 \%$ decreased the daily number of cigarettes smoked during the lockdown. Similarly, the overall frequency of alcohol consumption increased in $11.5 \%$ and decreased in $26 \%$ of participants, while the number of drinks consumed showed a similar pattern.

Regarding smoking, similar findings have been found in a study conducted during the COVID-19 lockdown in the US, where approximately a quarter of participants reduced smoking and a third increased their motivation to quit, whilst $30 \%$ increased their smoking [44]. A similar survey conducted across five countries (Italy, India, South Africa, UK, and US) including 6800 smokers under a variety of lockdown measures, found that ecigarette consumption marginally increased during lockdown [45]. The latter study also revealed that in-home smoking increased in Italy and India among exclusive tobacco cigarette smokers. Both studies note that smoking behaviour of participants was also affected by the perception of increased risk of infection or higher COVID-19 disease severity $[44,45]$. Although we did not assess perceptions of infection related to smoking, it is very likely that our participants who reduced or quit smoking during lockdown had similar concerns or that the strict Cyprus lockdown measures prevented social smoking.

Concerning alcohol, there are conflicting findings in the literature. Our study findings are in line with an Italian survey reporting a $36.8 \%$ reduction in alcohol intake, probably due to reduced social drinking [11]. Conversely, a study conducted in Poland reported an increase in alcohol consumption in approximately $14 \%$ of participants, although more pronounced in alcohol addicts [33]. Similarly, UK evidence on drinking habits during COVID-19 lockdown [46] saw elevation in the proportion of risky drinkers. This is in contrast to our findings, showing a much higher decrease than increase $(11.6 \%$ vs. $3.1 \%)$ in high-risk drinking ( $\geq 6$ alcoholic drinks on one occasion) during lockdown. Similarly, the ECLB-COVID19 International Online Survey also showed a reduction in binge drinking at a global level [30]. Similar to our findings, in the UK study the proportion of people drinking less during lockdown was similar or exceeded the proportion of those drinking more [46]. Furthermore, a survey conducted by the charity Alcohol Change UK [47] also revealed that one in five participants drunk as a response to stress or anxiety during the lockdown and more than one in three acted to manage their drinking, with 7\% stopping altogether. Of note, in our study the proportion of people reporting never drinking increased (36.2\% vs. $22.3 \%)$.

\section{Strengths and limitations}

Our study had a few strengths and limitations. The study used validated assessment tools to evaluate and compare habits across all lifestyle pillars before and during a strict lockdown in a relatively large group of participants. Despite the use of validated tools, recall bias cannot be excluded due to the self-reporting nature of the assessment tools and the fact that they are not designed to measure health behaviours in the past. Thus, the measurements of the outcomes in the period before lockdown might be less accurate although there is no reason to believe that such bias would have occurred differentially in regard to people's changes in health behaviours between the two time periods. The convenience sampling method, however, led to overrepresentation of female, well-educated and urban-living participants who were possibly more health conscious. Nonetheless, there was reasonably good representation of all ages $(12 \%$ of adult population over the age of 65) and income groups (median monthly income in Cyprus in first quadrant of 2020 was 2000 euros) [48]. However, despite our population not being representative of Cyprus, the adverse changes in the lifestyle habits seen during lockdown in our study would have probably been more pronounced in a lower socio-economic, less health-conscious population 
setting. Health related outcomes and particularly mental health have been more severely impacted by the pandemic in lower socioeconomic groups in a study of 1004 participants living in Vienna [49].

\section{Conclusions}

Our study findings suggest the potential diverse and interlinked effects of the COVID-19 pandemic and the relevant control measures on all six lifestyle medicine pillars. As the COVID-19 pandemic endpoint is not yet known and measures to control the spread of the SARS$\mathrm{CoV}-2$ virus, such as partial and total lockdowns, will continue, the design of interventions to promote positive lifestyle behaviours is crucial. Such interventions should: (a) support maintenance of "good" lifestyle habits, as in the good sleep quality and increased opportunities for walking seen in our population; (b) address longstanding needs and gaps, such as increasing adherence to the MD; and (c) deal with emerging needs, especially regarding the interlinked triad of stress, sleep and social connection. As the short- and long-term effects of the pandemic on chronic diseases are still unknown, supporting development of holistic lifestyle interventions is of paramount importance.

\section{Supplementary Information}

The online version contains supplementary material available at https://doi. org/10.1186/s12889-021-10863-0.

Additional file 1: Supplementary Figure 1. Dot plots showing Month before Lockdown and Month in Lockdown values for Mediterranean Diet Score, Physical Activity Score, PSS-14 score, PSQI score, Overall Support Index, Total number of cigarettes, cigars and e-cigarettes smoked, and AUDIT-C score.

Additional file 2: Table S1. Adherence to Mediterranean Diet before and during Lockdown. Table S2. Physical Activity levels before and during Lockdown. Table S3. Stress levels before and during Lockdown.

Table S4. Sleep before and during Lockdown. Table S5. Social Connections before and during Lockdown.

\section{Acknowledgements}

In acknowledgement of the contributions during participant recruitment and data cleaning of Aline Derlagen and Nathan Ushmantha Pinnawala of the University of Nicosia Medical School.

\section{Authors' contributions}

OK and MM prepared the first draft of the manuscript. OK and EP conceived the study and $C D, A Q, M M$ and $A H$ contributed towards the design. MM supervised the conduction of the study. CD and AQ performed the statistical analysis. All authors assisted in data interpretation and in drafting the manuscript. All authors have read and approved the final version of the manuscript.

\section{Funding}

The study was funded by the University of Nicosia.

\section{Availability of data and materials}

The datasets used and/or analysed during the current study are available from the corresponding author on reasonable request.

\section{Declarations}

Ethics approval and consent to participate

The study received approval by the Cyprus National Bioethics Committee (EEBK EП 2020.01.69) and permission for use of the validated assessment tools by the respective authors.

\section{Consent for publication}

The study does not include any materials such as pictures or videos relating to an individual, thus no consent for publication is required.

\section{Competing interests}

The authors declare no competing interests.

\section{Author details}

'Department of Primary Care and Population Health, Medical School, University of Nicosia, 21 llia Papakyriakou, 2414, Engomi, P.O. Box 24005, CY-1700 Nicosia, Cyprus. ${ }^{2}$ Department of Life and Health Sciences, School of Sciences and Engineering, University of Nicosia, Nicosia, Cyprus. ${ }^{3}$ Department of Nutritional Sciences, King's College London, London, UK.

Received: 18 January 2021 Accepted: 13 April 2021

Published online: 23 April 2021

\section{References}

1. Cucinotta D, Vanelli M. WHO declares COVID-19 a pandemic. Acta Biomed. 2020;91(1):157-60. https://doi.org/10.23750/abm.v91i1.9397.

2. Kumaresan J, Bolaji B, Kingsley JP, Sathiakumar N. Is the COVID-19 pandemic an opportunity to advance the global noncommunicable disease agenda? Int J Noncommun Dis. 2020;5(2):43.

3. Nyberg ST, Singh-Manoux A, Pentti J, Madsen IE, Sabia S, Alfredsson L, et al. Association of Healthy Lifestyle with years Lived without Major Chronic Diseases. JAMA Intern Med. 2020;180(5):760-8. https://doi.org/10.1001/jama internmed.2020.0618.

4. Vardavas Cl, Nikitara K. COVID-19 and smoking: a systematic review of the evidence. Tob Induc Dis. 2020;18. https://doi.org/10.18332/tid/119324.

5. Hamer M, Kivimäki M, Gale CR, Batty GD. Lifestyle risk factors, inflammatory mechanisms, and COVID-19 hospitalization: a community-based cohort study of 387,109 adults in UK. Brain Behav Immun. 2020;87:184-7. https:// doi.org/10.1016/j.bbi.2020.05.059.

6. Reddy RK, Charles WN, Sklavounos A, Dutt A, Seed PT, Khajuria A. The effect of smoking on COVID-19 severity: a systematic review and meta-analysis. J Med Virol. 2021;93(2):1045-56. https://doi.org/10.1002/jmv.26389.

7. Seidu S, Gillies C, Zaccardi F, Kunutsor SK, Hartmann-Boyce J, Yates T, et al. The impact of obesity on severe disease and mortality in people with SARSCoV-2: A systematic review and meta-analysis. Endocrinol Diabet Metabol. 2021:4(1):e00176.

8. Ren X. Pandemic and lockdown: a territorial approach to COVID-19 in China, Italy and the United States. Eurasian Geogr Econ. 2020:1-12. https://doi. org/10.1080/15387216.2020.1860786

9. Stanton R, To QG, Khalesi S, Williams SL, Alley SJ, Thwaite TL, et al. Depression, anxiety and stress during COVID-19: associations with changes in physical activity, sleep, tobacco and Alcohol use in Australian adults. Int J Environ Res Public Health. 2020;17(11):4065. https://doi.org/10.3390/ijerph1 7114065.

10. Giustino V, Parroco AM, Gennaro A, Musumeci G, Palma A, Battaglia G. Physical activity levels and related energy expenditure during COVID-19 quarantine among the Sicilian active population: a cross-sectional online survey study. Sustainability. 2020;12(11):4356. https://doi.org/10.3390/ su12114356.

11. Scarmozzino F, Visioli F. Covid-19 and the subsequent lockdown modified dietary habits of almost half the population in an Italian sample. Foods. 2020;9(5):675. https://doi.org/10.3390/foods9050675.

12. Stockwell $S$, Trott $M$, Tully M, Shin J, Barnett $Y$, Butler $L$, et al. Changes in physical activity and sedentary behaviours from before to during the COVID-19 pandemic lockdown: a systematic review. BMJ Open Sport Exerc Med. 2021;7(1):e000960. https://doi.org/10.1136/bmjsem-2020-000960.

13. Pérez-Rodrigo C, Gianzo Citores M, Hervás Bárbara G, Ruiz-Litago F, Casis Sáenz $L$, Arija V, et al. Patterns of Change in dietary habits and physical activity during lockdown in Spain due to the COVID-19 pandemic. Nutrients. 2021;13(2):300. https://doi.org/10.3390/nu13020300. 
14. Jahrami H, BaHammam AS, Bragazzi NL, Saif Z, Faris M, Vitiello MV. Sleep problems during the COVID-19 pandemic by population: a systematic review and meta-analysis. J Clin Sleep Med. 2021;17(2):299-313. https://doi. org/10.5664/jcsm.8930.

15. Brooks SK, Webster RK, Smith LE, Woodland L, Wessely S, Greenberg N, et al. The psychological impact of quarantine and how to reduce it: rapid review of the evidence. Lancet. 2020;395(10227):912-20. https://doi.org/10.1016/ S0140-6736(20)30460-8.

16. Zhao X, Lan M, Li H, Yang J. Perceived stress and sleep quality among the non-diseased general public in china during the 2019 coronavirus disease: a moderated mediation model. Sleep Med. 2020;77:339-45.

17. Casagrande M, Favieri F, Tambelli R, Forte G. The enemy who sealed the world: effects quarantine due to the COVID-19 on sleep quality, anxiety, and psychological distress in the Italian population. Sleep Med. 2020;75:12-20. https://doi.org/10.1016/j.sleep.2020.05.011.

18. Castillo CC. Analysis of the stress, anxiety and healthy habits in the Spanish Covid-19 confinement. Health Sci J. 2020;14(2):707.

19. Balanzá-Martínez V, Kapczinski F, de Azevedo CT, Atienza-Carbonell B, Rosa AR, Mota JC, et al. The assessment of lifestyle changes during the COVID-19 pandemic using a multidimensional scale. Rev Psiquiatr Salud Ment. 2021; 14(1):16-26. https://doi.org/10.1016/j.rpsm.2020.07.003.

20. López-Bueno R, Calatayud J, Casaña J, Casajús JA, Smith L, Tully MA, et al. COVID-19 confinement and health risk behaviors in Spain. Front Psychol. 2020;11:1426. https://doi.org/10.3389/fpsyg.2020.01426.

21. Guthrie GE. What is lifestyle medicine? Am J Lifestyle Med. 2018;12(5):363-4. https://doi.org/10.1177/1559827618759992.

22. Loef $\mathrm{M}$, Walach $\mathrm{H}$. The combined effects of healthy lifestyle behaviors on all cause mortality: a systematic review and meta-analysis. Prev Med. 2012; 55(3):163-70. https://doi.org/10.1016/j.ypmed.2012.06.017

23. Quattrocchi A, Mamais I, Tsioutis C, Christaki E, Constantinou C, Koliou M, et al. Extensive testing and public health interventions for the control of COVID-19 in the Republic of Cyprus between march and may 2020. J Clin Med. 2020;9(11):3598. https://doi.org/10.3390/jcm9113598.

24. García-Conesa M, Philippou E, Pafilas C, Massaro M, Quarta S, Andrade V, et al. Exploring the validity of the 14-item Mediterranean diet adherence screener (MEDAS): a cross-National Study in seven European countries around the Mediterranean region. Nutrients. 2020;12(10):2960. https://doi. org/10.3390/nu12102960.

25. Papathanasiou G, Georgoudis G, Papandreou M, Spyropoulos P, Georgakopoulos D, Kalfakakou V, et al. Reliability measures of the short international physical activity questionnaire (IPAQ) in Greek young adults. Hell J Cardiol. 2009 August 01;50(4):283-94.

26. Kotronoulas GC, Papadopoulou CN, Papapetrou A, Patiraki E. Psychometric evaluation and feasibility of the Greek Pittsburgh sleep quality index (GRPSQI) in patients with cancer receiving chemotherapy. Support Care Cancer. 2011;19(11):1831-40. https://doi.org/10.1007/s00520-010-1025-4

27. Katsarou A, Panagiotakos D, Zafeiropoulou A, Vryonis M, Skoularigis I, Tryposkiadis F, et al. Validation of a Greek version of PSS-14; a global measure of perceived stress. Cent Eur J Public Health. 2012;20(2):104-9. https://doi.org/10.21101/cejph.a3698.

28. Nicolaou C, Koula C, Papathanassoglou E. Cross-cultural applicability of the Medical Outcomes Study-social support survey as a measure of perceived social support among Greek-Cypriot Mothers. Alaska: 20th IEA World congress of epidemiology; 2014.

29. Saunders JB, Aasland OG, Babor TF, De La Fuente Juan R, Grant M. Development of the alcohol use disorders identification test (AUDIT): WHO collaborative project on early detection of persons with harmful alcohol consumption-II. Addiction. 1993;88(6):791-804. https://doi.org/10.1111/j.1360-0443.1993.tb02093.x.

30. Ammar A, Trabelsi K, Brach M, Chtourou H, Boukhris O, Masmoudi L, et al. Effects of home confinement on mental health and lifestyle behaviours during the COVID-19 outbreak: insight from the "ECLB-COVID19" multi countries survey. Nutrients. 2020;12(6):1583.

31. Sarri KO, Linardakis MK, Bervanaki FN, Tzanakis NE, Kafatos AG. Greek orthodox fasting rituals: a hidden characteristic of the Mediterranean diet of Crete. Br J Nutr. 2004;92(2):277-84. https://doi.org/10.1079/BJN20041197.

32. Di Renzo L, Gualtieri P, Pivari F, Soldati L, Attinà A, Cinelli G, et al. Eating habits and lifestyle changes during COVID-19 lockdown: an Italian survey. J Transl Med. 2020;18(1):1-15.

33. Sidor A, Rzymski P. Dietary choices and habits during COVID-19 lockdown: experience from Poland. Nutrients. 2020;12(6):1657. https:// doi.org/10.3390/nu12061657
34. Rodríguez-Pérez C, Molina-Montes E, Verardo V, Artacho R, García-Villanova B, Guerra-Hernández EJ, et al. Changes in dietary Behaviours during the COVID-19 outbreak confinement in the Spanish COVIDiet study. Nutrients. 2020;12(6):1730. https://doi.org/10.3390/nu12061730.

35. Maugeri G, Castrogiovanni P, Battaglia G, Pippi R, D'Agata V, Palma A, et al. The impact of physical activity on psychological health during Covid-19 pandemic in Italy. Heliyon. 2020;6(6):e04315. https://doi.org/10.1016/j. heliyon.2020.e04315.

36. Lesser IA, Nienhuis CP. The impact of COVID-19 on physical activity behavior and well-being of Canadians. Int J Environ Res Public Health. 2020; 17(11):3899. https://doi.org/10.3390/ijerph17113899.

37. El-Zoghby SM, Soltan EM, Salama HM. Impact of the COVID-19 pandemic on mental health and social support among adult Egyptians. J Community Health. 2020 August 01;45(4):689-95. https://doi.org/10.1 007/s10900-020-00853-5.

38. Xiao H, Zhang Y, Kong D, Li S, Yang N. Social capital and sleep quality in individuals who self-isolated for 14 days during the coronavirus disease 2019 (COVID-19) outbreak in January 2020 in China. Med Sci Monit. 2020;26:e923921.

39. Tull MT, Edmonds KA, Scamaldo K, Richmond JR, Rose JP, Gratz KL. Psychological outcomes associated with stay-at-home orders and the perceived impact of COVID-19 on daily life. Psychiatry Res. 2020;289:113098.

40. Groarke JM, Berry E, Graham-Wisener L, McKenna-Plumley PE, McGlinchey E, Armour C. Loneliness in the UK during the COVID-19 pandemic: crosssectional results from the COVID-19 psychological wellbeing study. PLoS One. 2020;15(9):e0239698. https://doi.org/10.1371/journal.pone.0239698.

41. Probst T, Budimir S, Pieh C. Depression in and after COVID-19 lockdown in Austria and the role of stress and loneliness in lockdown: a longitudinal study. J Affect Disord. 2020;277:962-3. https:/doi.org/10.1016/j.jad.2020.09.047.

42. Cellini N, Canale N, Mioni G, Costa S. Changes in sleep pattern, sense of time and digital media use during COVID-19 lockdown in Italy. J Sleep Res. 2020:e13074.

43. Fluharty M, Taylor AE, Grabski M, Munafò MR. The association of cigarette smoking with depression and anxiety: a systematic review. Nicotine Tobacco Res. 2016;19(1):3-13.

44. Klemperer EM, West JC, Peasley-Miklus C, Villanti AC. Change in tobacco and electronic cigarette use and motivation to quit in response to COVID-19. Nicotine Tobacco Res. 2020;22(9):1662-3. https://doi.org/10.1093/ntr/ntaa072.

45. Yach D. Tobacco use patterns in five countries during the COVID-19 lockdown. Nicotine Tob Res. 2020;22(9):1671-2. https://doi.org/10.1093/ntr/ntaa097.

46. Institute of Alcohol Studies. Alcohol consumption during the COVID-19 pandemic in the UK. Second IAS briefing. Available at: https://movendi.ngo/ wp-content/uploads/2020/10/IAS-2nd-Briefing-on-alcohol-consumptionduring-COVID-19-in-UK.pdf. Accessed Dec 2020.

47. Alcohol Change UK. Research: Drinking in the UK during Lockdown and Beyond. Available at: https://alcoholchange.org.uk/blog/2020/drinking-inthe-uk-during-lockdown-and-beyond. Accessed Dec 2020.

48. Cyprus Statistical Service. Demographic Statistics. 2019. Available at: https:// www.mof.gov.cy/mof/cystat/statistics.nsf/All/6C25304C1E70C304C2257833 003432B3/\$file/Demographic_Statistics_Results-2019-EN-301120. pdf?OpenElement.

49. Oberndorfer M, Dorner T, Brunnmayr M, Berger K, Dugandzic B, Bach M. Equally Affected? Health-Related and Socioeconomic Adversities of the COVID-19 Pandemic in Vienna; 2020.

\section{Publisher's Note}

Springer Nature remains neutral with regard to jurisdictional claims in published maps and institutional affiliations.

\section{Ready to submit your research? Choose BMC and benefit from:}

- fast, convenient online submission

- thorough peer review by experienced researchers in your field

- rapid publication on acceptance

- support for research data, including large and complex data types

- gold Open Access which fosters wider collaboration and increased citations

- maximum visibility for your research: over $100 \mathrm{M}$ website views per year

At $\mathrm{BMC}$, research is always in progress.

Learn more biomedcentral.com/submissions 